\title{
Designing an Automatic Wall Follower with Remote Operation for Manual Movement
}

Ruwan Bolongho ${ }^{1}$

${ }^{1}$ Affiliation not available

November 18, 2021

\section{Hosted file}

Designing an Automatic Wall Follower with Remote Operation for Manual Movement.pdf available at https://authorea.com/users/441907/articles/546013-designing-an-automatic-wallfollower-with-remote-operation-for-manual-movement 